\title{
THE EFFECT OF THE ENTRY HOLE FOR AN INTRAMEDULLARY NAIL ON THE STRENGTH OF THE PROXIMAL FEMUR
}

\author{
S. D. MILlER, B. BURKART, E. DAMSON, N. SHRIVE, R. C. BRAY
}

From the University of Calgary, Canada

We used 15 pairs of femora from fresh human cadavers to study the effects of the size and location of the entry hole for an intramedullary nail on the strength of the femur. Right femora were used as controls. Left femora in group $1 \mathrm{had}$ a $10 \mathrm{~mm}$ entry hole in the 'ideal' location in the piriformis fossa. Group 2 had a $14 \mathrm{~mm}$ entry hole in the same position and group $3 \mathrm{had}$ a $14 \mathrm{~mm}$ entry hole anterior to this on the superior aspect of the femoral neck. Femora were equipped with strain gauges and loaded to failure in compression.

There was reduced stifiness and load to failure in group 3 specimens, suggesting that the location of the hole was more important than its size.

J Bone Joint Surg [Br] 1993; 75-B:202-6.

Received 20 February 1992; Accepted 13 July 1992

S. D. Miller, MD, FRCS C, Assistant Clinical Professor

B. Burkart, MD, FRCS C, Clinical Lecturer

Department of Surgery

R. C. Bray, MD, FRCS C, Assistant Professor

Department of Surgery and Joint Injury and Diseases Research Group

N. Shrive, D Phil, Professor and Head

Department of Civil Engineering

E. Damson, Senior Research Technician

Department of Civil Engineering

University of Calgary, 140329 th Street NW, Calgary, Alberta, Canada

T2N 2 T9.

Correspondence should be sent to Dr S. D. Miller.

(C)1993 British Editorial Society of Bone and Joint Surgery $0301-620 \mathrm{X} / 93 / 2510 \$ 2.00$
Closed intramedullary nailing is widely used in the treatment of femoral shaft fractures (Kempf, Grosse and Lafforgue 1978; Brumback et al 1988a,b; Christie and Court-Brown 1988; Christie et al 1988; Fein et al 1989; Kaltenecker, Wruhs and Quaicoe 1990). The method is technically demanding and complications include fracture of the femoral neck, avascular necrosis of the femoral head and septic arthritis from intra-articular penetration (Böstman et al 1989). To avoid these, Küntscher (1967) originally chose the tip of the greater trochanter as the entry site. This, however, is often lateral to the central axis of the medullary canal and nails inserted here tend to impinge against the medial cortex and may cause comminution of the proximal fragment. The use of a more medial entry site, in the region of the piriformis fossa, reduces this complication (Brumback et al 1988a,b).

However, femoral neck fractures have been reported after closed nailing (Böstman et al 1989; Brumback et al 1989 ) and approached $3 \%$ in one series (Brumback et al 1988). There are also several reports of ipsilateral femoral neck and shaft fractures (Küntscher 1967; Schatzker and Barrington 1968; Bernstein 1974; Ashby and Anderson 1977; Browner 1986; Johnson and Greenberg 1987; Johnson, Tencer and Sherman 1987; Christie and CourtBrown 1988; Hooper and Lyon 1988). In some of these the femoral neck fracture may have been caused by the treatment of the femoral shaft fracture (Küntscher 1967; Christie and Court-Brown 1988; Hooper and Lyon 1988), and may be related to the site and size of the entry hole for femoral nailing.

We therefore set out to test the hypothesis that the entry hole for femoral nailing could affect the failure behaviour of the femoral neck.

\section{MATERIALS AND METHODS}

We obtained 15 pairs of femora from fresh adult cadavers with no history of malignant disease. They were aged 60 to 92 years (mean 76.7). All femora were radiographed to 


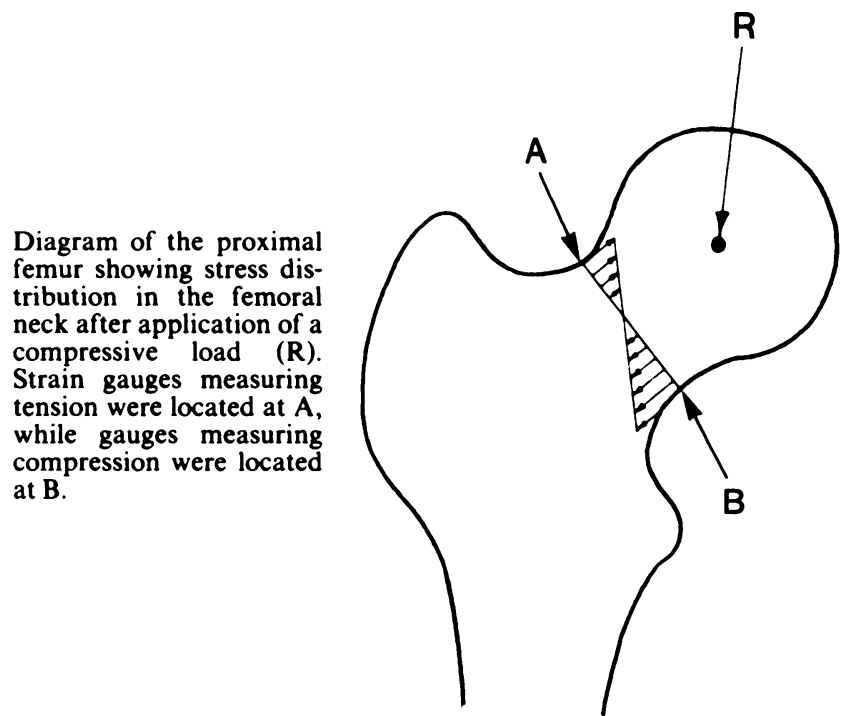

Fig. 1

exclude tumour, previous fracture, or obvious osteopenia. They were stripped of soft tissues, stored at $-20^{\circ} \mathrm{C}$ and thawed at room temperature immediately before testing.

The load-strain characteristics of the femur under test were measured by strain gauges applied to the superior and inferior aspects of the femoral neck (Fig. 1). An inferior gauge, measuring compressive strains, was applied to all specimens (Wright and Hayes 1979); superior gauges, measuring tensile strains, were used only if there was adequate space on the neck after drilling the entry hole. The femur was placed in an Instron materials-testing machine, with the load directed from the femoral head through the femoral condyles, to simulate two-legged stance. A special frame was designed to ensure stable fixation of the femur and to allow reproducible application of load, and polymethylmethacrylate was used to supplement fixation of the distal femoral condyles. The 15 pairs of femora were randomly separated into three groups of five; the right femora served as the control and was tested to failure with no entry holes.

In group 1, both right and left femora had strain gauges to measure tension and compression. The left femur, while still intact, was compressed to $60 \%$ of the failure load of the corresponding right femur, to detect any intrinsic differences between the pair. It was then unloaded and a $10 \mathrm{~mm}$ entry hole was created in the 'ideal' location in the region of the piriformis fossa (Fig. 2), using a standard drill bit passed to the level of the lesser trochanter. The drilled left femur was then compressed to failure.

In group 2, only left femora were equipped with strain gauges. Intact left femora were compressed to $60 \%$ of the failure load of the corresponding right femur then unloaded. A $10 \mathrm{~mm}$ entry hole was created and loading to $60 \%$ of right failure load was repeated. The specimen was again unloaded and the hole enlarged to $14 \mathrm{~mm}$ before the femur was compressed to failure.
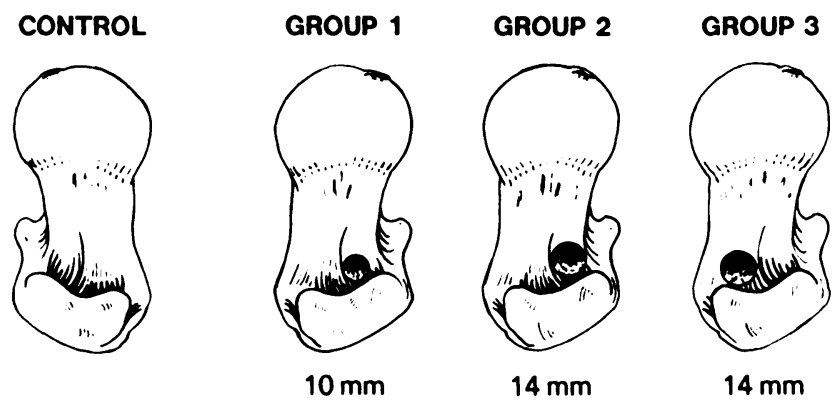

Fig. 2

Diagrams to show the various entry hole sizes and locations. Group 1 had a $10 \mathrm{~mm}$ entry hole in the 'ideal' location in the piriformis fossa. Group 2 had a $14 \mathrm{~mm}$ entry hole at the same site. Group 3 had a $14 \mathrm{~mm}$ entry hole more anteriorly on the superior aspect of the femoral neck.

In group 3, only left femora were equipped with compression gauges, since the proposed entry-hole site prevented the proper placement of tension-measuring strain gauges. Again, intact left femora were loaded to $60 \%$ of the failure load, and unloaded before a $14 \mathrm{~mm}$ entry hole was made anterior to the 'ideal' location on the superior aspect of the femoral neck (Fig. 2). The femur was then loaded to failure. Superior views of group 1 and group 3 femoral necks are shown in Figure 3.

For each group we recorded failure load, strain and stiffness and obtained composite load-strain curves for all left specimens. Similar data were collected for the five right femora in group 1, but only failure loads were obtained for the right femora in groups 2 and 3.

Statistical analysis was by one-way analysis of variance after Student-Newman-Keul's procedure for multiple comparisons, with a significance level of $\mathrm{p}<0.05$. Comparisons were performed between all experimental groups, and these were also compared with pooled control results.

\section{RESULTS}

There were consistent modes of failure. All the rightsided control femora sustained an oblique subcapital fracture, and all left femora, regardless of hole size or placement, failed by a basicervical fracture through the drill hole (Fig. 4).

The prefailure loading tests of all left femora compressed to $60 \%$ of the right-sided failure load showed no significant differences in force-strain behaviour within pairs. Forces at failure for left femora in groups 1 and 2 were similar to each other and to the mean of their control femora (Fig. 5), with averages of $104 \%$ and $98 \%$, respectively, of the control values. By contrast, left femora from group 3 failed at a mean of two-thirds of the control values, but the large variation meant that no statistically significant differences were identified for femur failure force. We found no significant differences in failure strains between any of the groups or with the controls. 
Views of two femoral necks to show entry hole sizes and locations: A Group 1 , ideal location, $10 \mathrm{~mm}$ hole. B - Group 3, anterior location, $14 \mathrm{~mm}$ hole.
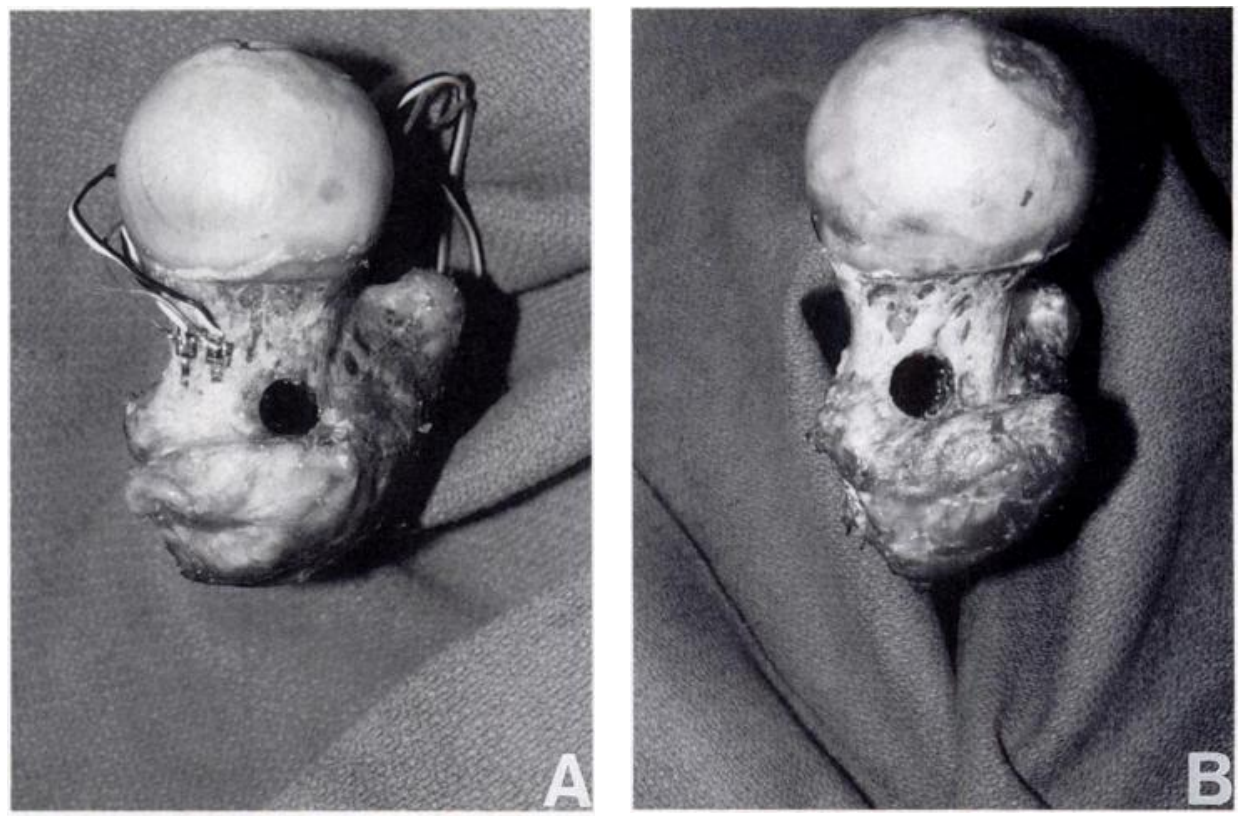

Fig. 3

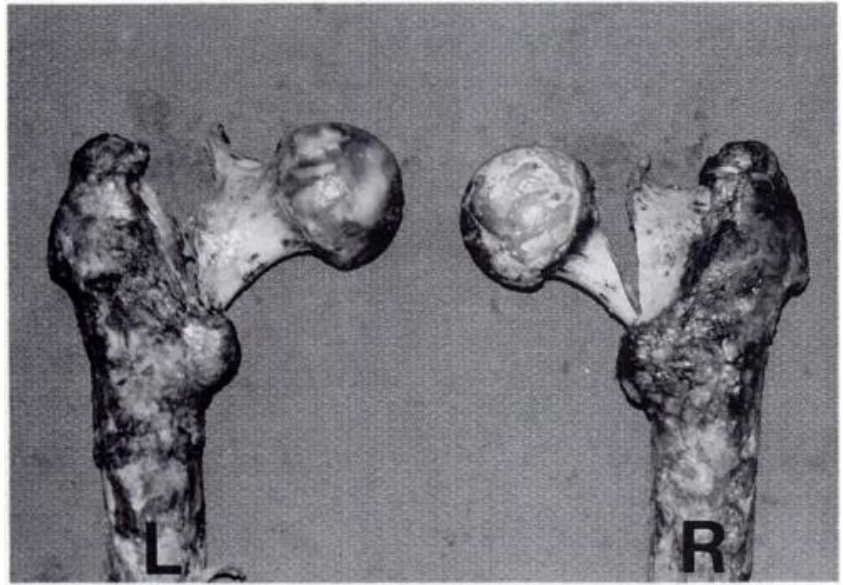

Fig. 4

Posterior view of left (L) and right (R) specimens showing typical fracture patterns. The left specimen has a basicervical fracture passing through the entry hole (not visible). On the right there is a typical oblique subcapital fracture seen in all control specimens.

Composite force-strain relationships computed from tests of all three groups are shown in Figures 6,7 and 8. Similar stiffness in both tension and compression was recorded for left and right (control) femora from group 1 (Fig. 6), and similar curves were observed for the left femora in group 2 (Fig. 7).

In groups 1 and 2 , it was apparent that the variation of entry-hole size from $10 \mathrm{~mm}$ to $14 \mathrm{~mm}$ in the 'ideal' location had a negligible effect. The left femora in group 3 , however, showed the definite effect of improper hole placement on compressive force-strain behaviour when compared with control values (Fig. 8a). The stiffness modulus of the force-strain curves is shown in Figure 8b: the only significant difference was with the gauge

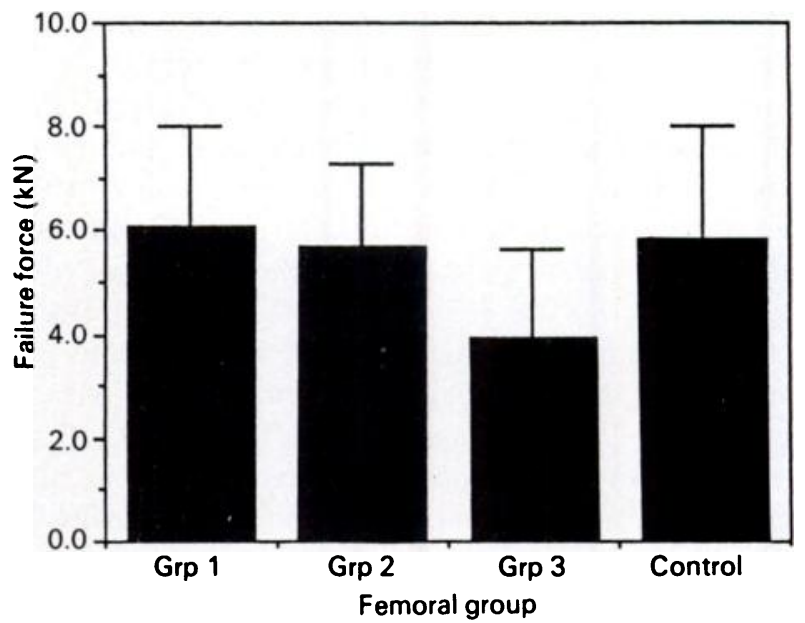

Fig. 5

Mean force at failure for each group of femora. There were no significant differences between groups or with the controls, although group 3 failure forces were only two-thirds of control values.

measuring compression on the inferior aspect of the femoral neck. The data from this gauge showed that femora in group 3 were significantly less stiff than those in group 2.

\section{DISCUSSION}

Fractures of the femoral neck may sometimes be associated with technical errors during closed nailing of the femoral shaft (Harper and Henstorf 1986) and the introduction of an entry hole in the femoral neck must introduce a new stress riser that may affect its structural behaviour (Seligson 1985; Johnson and Greenberg 1987; Johnson et al 1987). 


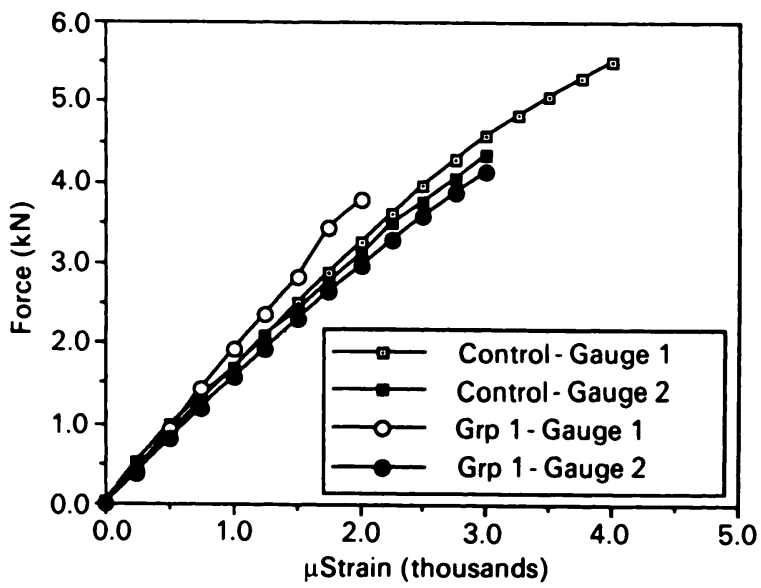

A

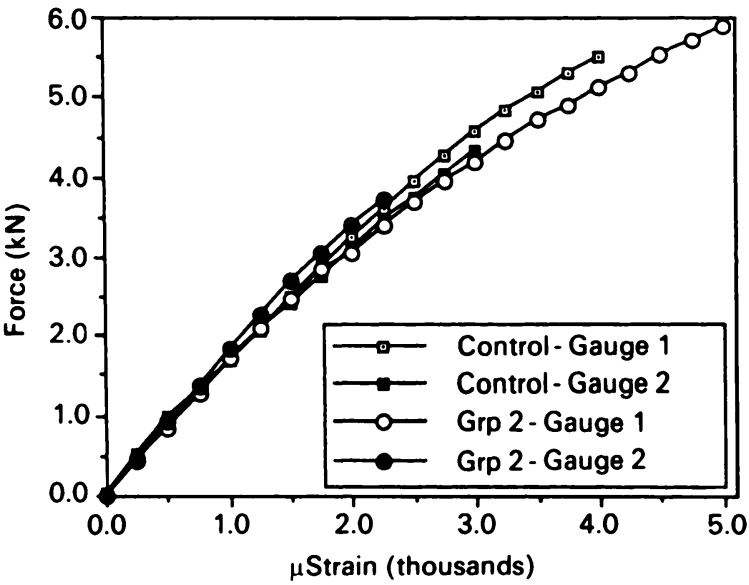

A

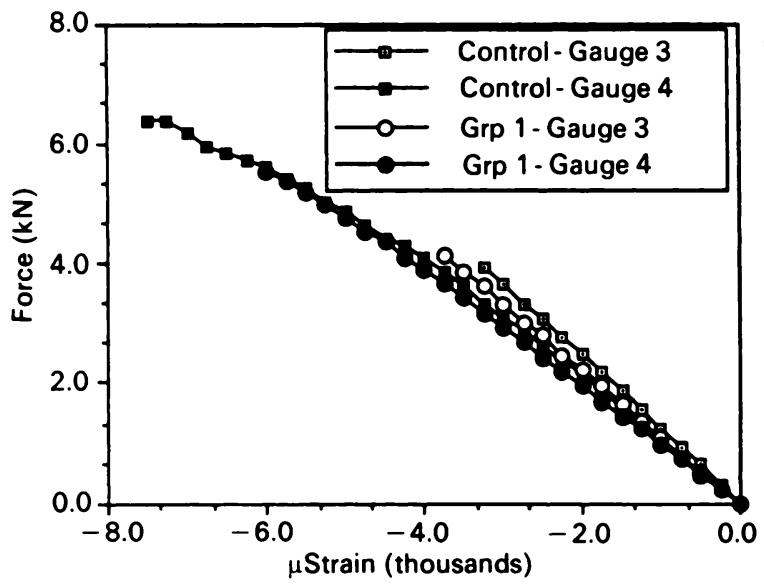

Fig. 6

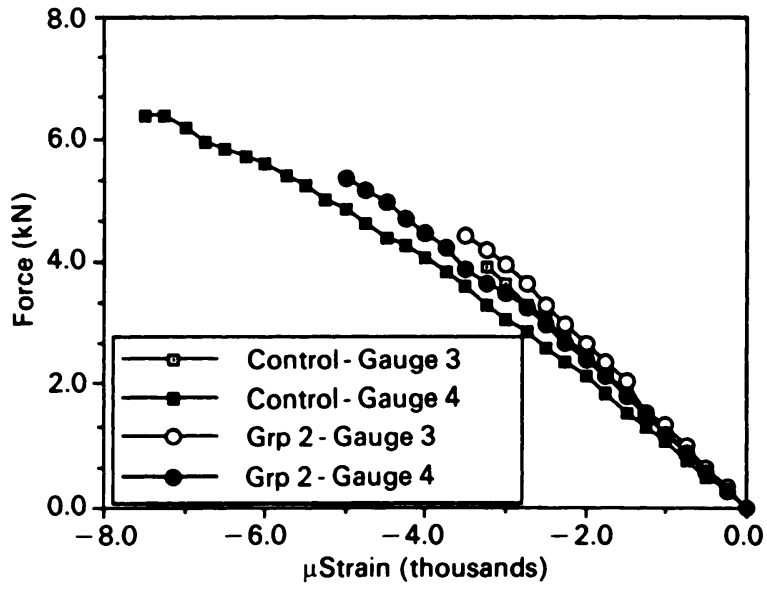

B

Fig. 7

Force-strain curves for group 1 femora showing tensile (A) and compressive (B) behaviour. There were no significant differences between group $I$ and control femora.

Force-strain curves for group 2 femora showing tensile (A) and compressive (B) behaviour. There were no significant differences between group 2 and control femora.

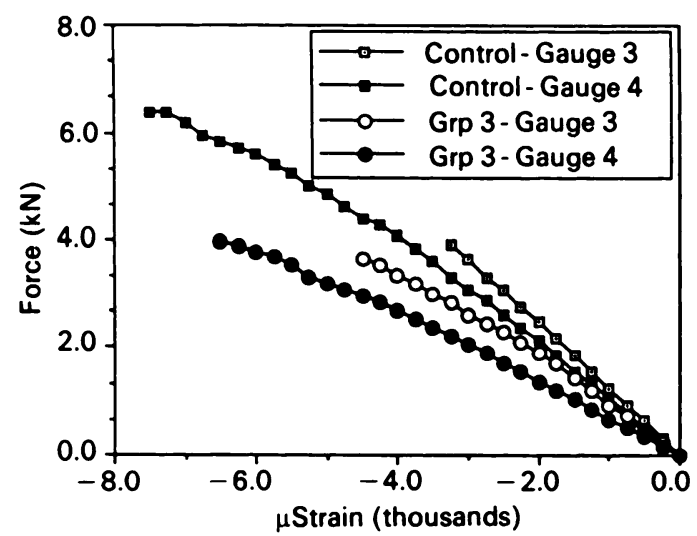

Fig. 8a

Force-strain curves for group 3 femora showing behaviour under compression. There were no significant differences, but a trend towards lower stiffness after larger and superior entry-hole placement.

A

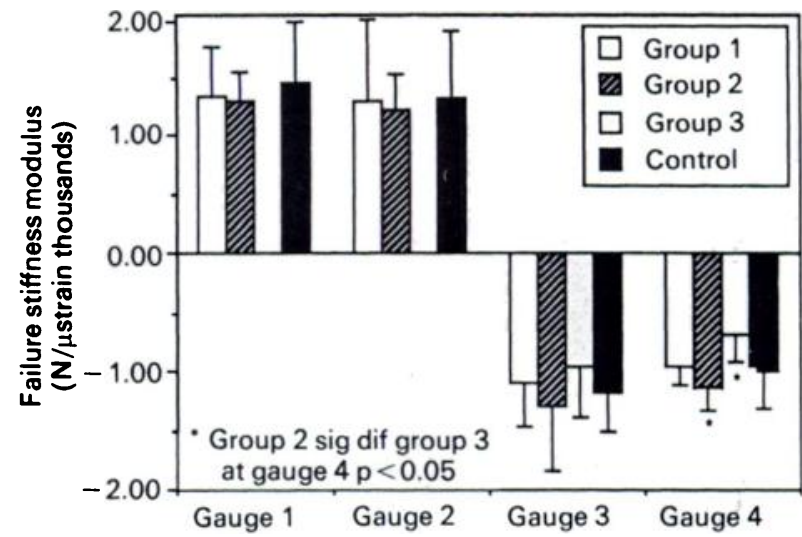

Fig. 8b

Stiffness by the slope of force-deformation plots between 1000 and 3000 microstrain for all groups for all gauges. The only significant difference was between groups 2 and 3 for gauge 4 values. 
Our experimental results suggest that the biomechanics of the femoral neck change subtly after the placement of an entry hole for an intramedullary nail. The most obvious change was that of the pattern of fracture. All femora with drill holes failed by a basicervical fracture through the drill hole while all control femora failed by an oblique subcapital fracture.

However, an ideally placed drill hole in the piriformis fossa, of either size ( $10 \mathrm{~mm}$ or $14 \mathrm{~mm})$, had a minimal effect on the structural behaviour of the femoral neck, in that the failure force, strain and stiffness properties of groups 1 and 2 were very similar to those of control femora. By contrast, group 3 femora, with any entry hole anterior to the 'ideal' location were significantly less stiff than group 2 femora, and failed at two-thirds of control values (not significant). It appears that under the loading system that we used, the anterior portion of the femoral neck is a more important load-carrying component than the posterior portion, and that entry-hole placement has a more marked effect than entry-hole size.

Our study simplified the clinical situation in several respects. We used $10 \mathrm{~mm}$ and $14 \mathrm{~mm}$ hole sizes, but should perhaps have chosen the nail size from radiographs so that the size of entry hole was appropriate for each pair of femora. We also tested femora with no intramedullary nail, used specimens from an elderly age group, and did not study the effect of repetitive loading to simulate walking. Despite these limitations, our results suggest that care is required in the placement of the entry hole for intramedullary nailing.

The authors gratefully acknowledge the financial assistance of Richards Medical and The Arthritis Society of Canada. We are also grateful to Laural McDonald for her help in the completion of this manuscript.

Although none of the authors have received or will receive benefits for personal or professional use from a commercial party related directly or indirectly to the subject of this article, benefits have been or will be received but are directed solely to a research fund, foundation, educational institution, or other non-profit institution with which one or more of the authors is associated.

\section{REFERENCES}

Ashby ME, Anderson JC. Treatment of fractures of the hip and ipsilateral femur with the Zickel device: a report of three cases. Clin Orthop 1977; 127:156-60.
Bernstein SM. Fractures of the femoral shaft and associated ipsilateral fractures of the hip. Orthop Clin North Am 1974; 5:799-818.

Böstman O, Varjonen L, Vainionpää S, et al. Incidence of local complications after intramedullary nailing and after plate fixation of femoral shaft fractures. J Trauma 1989;29:639-45.

Browner BD. Pitfalls, errors, and complications in the use of locking Küntscher nails. Clin Orthop 1986; 212:192-208.

Brumback RJ, Reilly JP, Poka A, et al. Intramedullary nailing of femoral shaft fractures. Part I. Decision making errors with interlocking fixation. J Bone Joint Surg [Am] 1988a; 70-A: 1441-52.

Brumback RJ, Uwagie-Ero S, Lakatos RP, et al. Intramedullary nailing of femoral shaft fractures. Part II. Fracture-healing with static interlocking fixation. J Bone Joint Surg [Am] 1988b; 70-A: 1453-62.

Brumback RJ, Ellison PS Jr, Poka A, et al. Intramedullary nailing of open fractures of the femoral shaft. J Bone Joint Surg [ Am] 1989; 71-A :1324-31.

Christie J, Court-Brown C, Kinninmonth AWG, Howie CR. Intramedullary locking nails in the management of femoral shaft fractures. J Bone Joint Surg [ Br] 1988; 70-B :206-10.

Christie J, Court-Brown C. Femoral neck fracture during closed medullary nailing: brief report. J Bone Joint Surg [Br] 1988; 70B : 670 .

Fein LH, Pankovich AM, Spero CM, Baruch HM. Closed flexible intramedullary nailing of adolescent femoral shaft fractures. J Orthop Trauma 1989; 3:133-41.

Harper MC, Henstorf J. Fractures of the femoral neck associated with technical errors in closed intramedullary nailing of the femur: report of two cases. J Bone Joint Surg [Am] 1986; 68-A :624-6.

Hooper GJ, Lyon DW. Closed unlocked nailing for comminuted femoral fractures. J Bone Joint Surg [Br] 1988; 70-B:619-21.

Johnson KD, Tencer AF, Sherman MC. Biomechanical factors affecting fracture stability and femoral bursting in closed intramedullary nailing of femoral shaft fractures, with illustrative case presentations. J Orthop Trauma 1987; 1:1-11.

Johnson KD, Greenberg M. Comminuted femoral shaft fractures. Orthop Clin North Am 1987; 18:133-47.

Kaltenecker G, Wruhs O, Quaicoe S. Lower infection rate after interlocking nailing in open fractures of femur and tibia. J Trauma $1990 ; 30: 474-9$.

Kempf I, Grosse A, Lafiorgue D. L'apport due verrouillage dans l'enclouage centro-médullaire des os longs. Rev Chir Orthop 1978; $64: 635-51$.

Küntscher G. Practice of intramedullary nailing. Springfield: Charles C Thomas, 1967

Schatzker J, Barrington TW. Fractures of the femoral neck associated with fractures of the same femoral shaft. Can J Surg 1968; 11: 297-305.

Seligson D. Concepts in intramedullary nailing. Orlando, etc: Grune \& Stratton, 1985.

Wright TM, Hayes WC. Strain gauge application on compact bone. J Biomech 1979; 12:471-5. 